\title{
MODIFICATION OF ROTOR BLADES SHAPE OF VERTICAL AXIS WIND TUBINE (VAWT)
}

\author{
Buyung Junaidin
}

Departemen Teknik Dirgantara, Sekolah Tinggi Teknologi Adisutjipto

Jl. Janti Blok-R Lanud Adisutjipto Yogyakarta

buyung112011@gmail.com

\begin{abstract}
Vertical Axis Wind Turbine (VAWT) has been develop due to design criteria and performance consideration as need like Darrieus's design with H-rotor shaped, V-rotor shaped and Troposkein shaped and Gorlov's design with helical rotor shaped. The aim of research is modification of rotor blades shape of existing mini scale VAWT, from straight shaped to helical shaped to increase aerodynamics performance of the VAWT rotor blades. Aerodynamics performance analysis of VAWT rotor performs with double-multiple streamtube (DMS) approach with varying the helical angle $45^{\circ}, 60^{\circ}, 75^{\circ}, 90^{\circ}, 105^{\circ}$ and $120^{\circ}$. From performance analysis, it shows that the helical shaped of rotor blades doesn't effect to the power coefficient of VAWT rotor, but it makes torsion of the rotors still in same way for all rotating angles which can hold the rotor rotation for power constant. For straight shaped blades, torsion is not in the same way for all rotating angles which yields unsteady power. From analysis, it can conclude that the rotor with $45^{\circ}$ helical angle blades is the best among other helical angles, which have highest torsion with constant power.
\end{abstract}

Keyword: Blades, Modification, Helical, VAWT.

Abstrak

Vertical Axis Wind Turbine (VAWT) telah dikembangkan berdasarkan kriteria desain dan pertimbangan performa yang diinginkan seperti desain Darrieus dengan bentuk rotor- $\mathrm{H}$, bentuk rotor-V dan bentuk rotor-Troposkein dan desain Gorlov dengan bentuk rotor-helix. Penelitian ini fokus pada modifikasi bentuk bilah rotor VAWT skala kecil yang telah dibuat sebelumnya dari bentuk lurus (straight shaped) menjadi bentuk puntir (helical shaped) untuk meningkatkan performa aerodinamika bilah rotor VAWT. Analisis performa aerodinamika rotor VAWT dilakukan menggunakan pendekatan model double-multiple stream-tube (DMS). Analisis dilakukan dengan variasi sudut puntir bilah sebesar $45^{\circ}, 60^{\circ}, 75^{\circ}, 90^{\circ}, 105^{\circ}$ dan $120^{\circ}$. Hasil analisis performa rotor menunjukkan bentuk puntir bilah tidak mempengaruhi besar nilai koefisien power turbin angin yang dihasilkan rotor, tetapi torsi yang dihasilkan oleh bilah puntir untuk semua sudut putar memiliki arah yang sama yang dapat mempertahankan putaran turbin yang menghasilkan power yang konstan, berbanding terbalik dengan bentuk bilah lurus. Dari semua sudut puntir yang dianalisis, disimpulkan bahwa sudut puntir yang menghasilkan nilai torsi besar dan power konstan adalah sudut puntir $45^{\circ}$.

Kata Kuci: Bilah, Modifikasi, Puntir, VAWT.

\section{Pengantar}

Konversi energi angin menjadi topik yang berkembang di seluruh dunia dalam dua dekade terakhir. Perkembangan ini ditandai dengan pembuatan dan pengembangan teknologi turbin angin berbagai jenis dan tujuan. Ketertarikan terhadap pemanfaatan energi angin mendorong kegiatan penelitian dalam teknologi turbin angin alternatif, seperti turbin angin untuk perairan dalam lepas pantai (deep-water off-shore) dengan model terapung dan turbin angin khusus untuk atap gedung di lingkungan perkotaan (building augmented-roof 
instalation-urban environtment). Untuk dua kasus tersebut teknologi turbin angin poros vertikal atau vertical axis wind tubine (VAWT) menawarkan banyak kelebihan dibandingkan turbin angin poros horizontal, antara lain tidak berpengaruh pada arah angin (dapat beroperasi pada berbagai arah angin), kebisingan lebih rendah karena tip speed rasio (TSR) lebih kecil dan untuk skala besar penempatan sistem mekanis dan elektriknya dapat ditempatklan di dasar (ground). Berbagai macam desain bentuk rotor dari VAWT telah dikembangkan berdasarkan kriteria desain dan pertimbangan performa yang diinginkan seperti desain Darrieus dengan bentuk rotor- $\mathrm{H}$, bentuk rotor- $\mathrm{V}$ dan bentuk rotor-Troposkein dan desain Gorlov dengan bentuk rotor-helix. Berbagai bentuk desain rotor VAWT dapat dilihat pada Gambar 1.

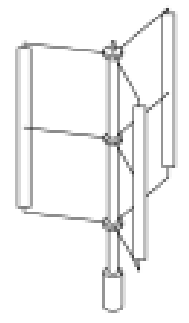

(a)

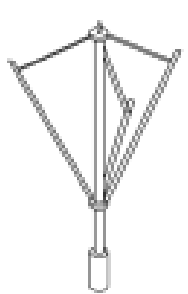

(b)

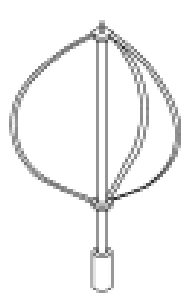

(c)

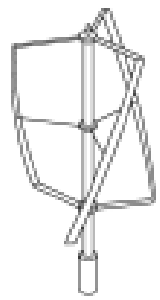

(d)

Gambar 1. Berbagai macam bentuk bilah VAWT

Sejak tahun 1931 desain bentuk rotor VAWT telah dipatenkan oleh G.J.M. Darrieus untuk rotor-Troposkien, rotor- $\mathrm{H}$ dan rotor- $\mathrm{V}$, namun seiring berkembangnya teknologi bentuk-bentuk awal rotor ini telah mengalami pengembangan dengan tujuan optimasi performa aerodinamika dan struktur dari rotor itu sendiri. Untuk alasan performa, sampai saat ini bentuk bilah melengkung menjadi pilihan utama untuk aplikasi VAWT.

Turbin angin tipe Darrieus memiliki karakteristik yaitu memanfaatkan gaya aerodinamika dalam beroperasi. Berdasarkan bentuk rotornya, terdapat periode dalam pemanfaatan angin oleh setiap bilah selama turbin berputar, hal ini menjadi kekurangan bagi turbin itu sendiri karena pada satu periode tidak semua bilah menghasilkan gaya aerodinamika yang dapat memutar turbin. Kekurangan ini disempurnakan oleh A. Gorlov dengan mengembangkan turbin angin dengan bentuk bilah puntir (helical shaped) berbasis bentuk rotor-H dari tipe Darrieus, kemudian dipatenkan pada pertengahan tahun 1990 untuk aplikasi hidrodinamika dan baru diadaptasi untuk aplikasi turbin angin sejak awal tahun 2000.

Penelitian ini fokus pada modifikasi bentuk bilah rotor VAWT skala kecil yang telah dibuat sebelumnya dari bentuk lurus (straight shaped) menjadi bentuk puntir (helical shaped) untuk meningkatkan performa bilah rotor VAWT. Analisis performa rotor VAWT dilakukan menggunakan pendekatan model double-multiple stream-tube (DMS.

\section{Metodologi Penelitian}

Ada empat pendekatan yang bisa digunakan untuk memodelkan performa aerodinamika dari suatu VAWT yaitu [1]:

1. Momentum model

2. Vortex model

3. Local circulation model

4. Viscous Model-Computational Fluid Dynamics (CFD)

Dalam penelitian ini model yang digunakan adalah double-multiple stream-tube atau biasa dikenal dengan model DMS yang termasuk kategori momentum model. Model DMS berdasarkan prinsip konservasi momentum yang diturunkan dari persamaan hukum Newton 
kedua. Model ini telah sukses untuk memprediksi torsi dan beban thrust dari rotor tipe Darrieus. Ilustrasi penggunaan model DMS untuk analisis VAWT dapat dilihat pada Gambar 2.

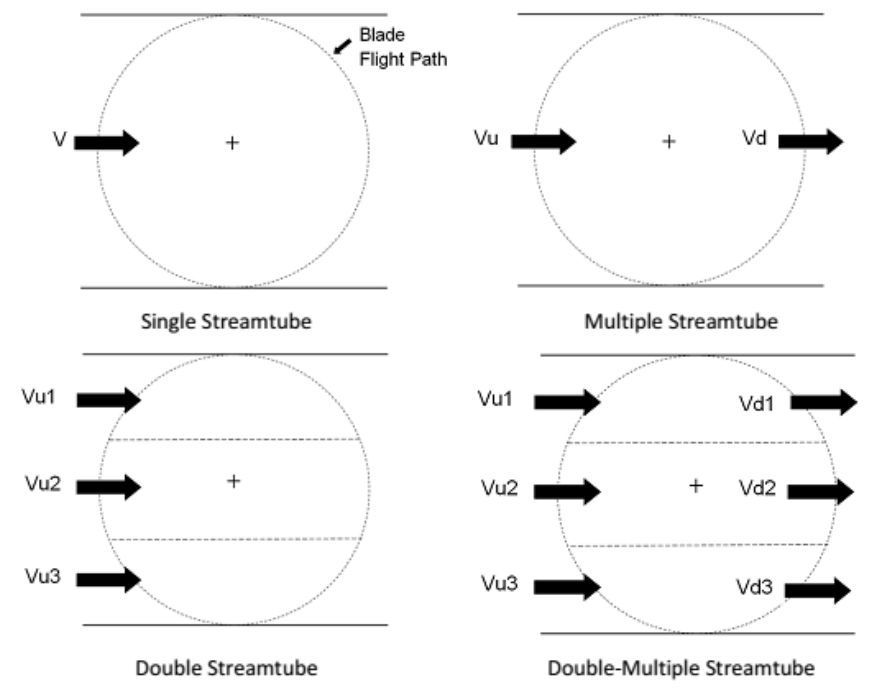

Gambar 2. Model stream-tube untuk analisis VAWT

Model DMS dikembangkan oleh I. Paraschivoiu untuk menghitung beban aerodinamika blade dan performa rotor pada VAWT tipe Darrieus dengan konfigurasi straight blade dan curve blade [2]. Model MDS mengaplikasikan teori piringan aktuator pada upstream dan downstream dari rotor. Teori ini menganggap turbin angin sebagai sebuah piringan yang menciptakan perubahan diskontinuitas tekanan dari aliran udara yang melewati stream-tube. Perubahan tekanan ini mengakibatkan perlambatan kecepatan udara yang menghasilkan kecepatan induce.

Swept area dibagi menjadi beberapa stream-tube dan didefinisikan oleh sudut ${ }^{\theta}$ yang merupakan sudut antara arah datang angin dengan posisi stream-tube pada rotor seperti yang ditunjukkan pada Gambar 3.

Analisis kondisi aliran udara dilakukan untuk setiap stream-tube dengan menggunakan kombinasi dari teori momentum dan teori blade elemen, selanjutnya menggunakan prinsip konservasi momentum. Setelah itu, blade dibagi menjadi ${ }^{N}$ elemen dan analisis gaya (lift dan drag) pada blade yang merupakan fungsi dari bentuk blade.

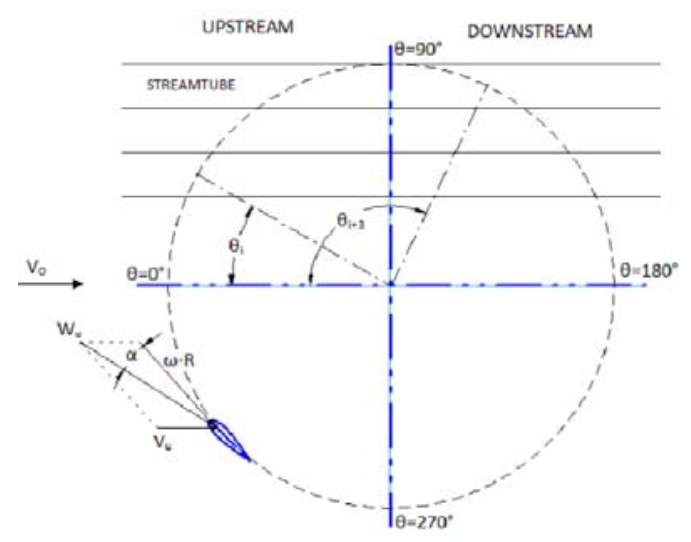

Gambar 3. Pembagian swept area menjadi stream-tube

Kecepatan induce berkurang pada arah aksial stream-tube. Kecepatan induce pada daerah upstream rotor dapat dinyatakan dalam persamaan 1.

$$
V_{u}=V_{o} a_{u}
$$


Dimana $V_{u}$ adalah kecepatan induce upstream, $V_{o}$ adalah kecepatan angin dan $a_{u}$ adalah faktor gangguan upstream yang nilainya kurang dari 1 .

Pada daerah tengah antara upstream dan downstream terdapat kecepatan induce equilibrium yang dinyatakan dengan persamaan 2 .

$$
V_{v}=V_{o}\left(2 a_{u}-1\right)
$$

Pada daerah downstream rotor, kecepatan induce dinyatakan dengan persamaan 3.

$$
V_{d}=V_{e} a_{d}
$$

Dimana $V_{d}$ adalah kecepatan induce downstream dan $a_{a}$ adalah faktor gangguan downstream yang nilainya lebih kecil dari ${ }^{a_{u}}$.

Dengan mengetahui kecepatan induce pada setiap daerah putaran blade maka dapat diketahui kecepatan resultan sehingga dapat dihitung gaya lift dan drag untuk setiap posisi blade yang kemudian dipakai untuk menghitung torsi dan koefisien power dari turbin angin.

Kecepatan resultan aliran udara dipengaruhi oleh kecepatan induce dan TSR lokal seperti dalam persamaan 4 .

$$
W_{u}=\sqrt{V_{u}^{2}\left[\left(T S R-\sin ^{2} \theta\right)^{2}+\cos ^{2} \theta\right]}
$$

Dimana $W_{u}$ adalah kecepatan aliran udara resultan dan ${ }^{T S R}$ lokal didefinisikan dalam persamaan 5 .

$$
T S E=R \frac{w}{V_{u}}
$$

$\operatorname{Dimana}^{R}$ adalah radius rotor dan ${ }^{\omega}$ adalah kecepatan putar rotor.

Kecepatan aliran udara resultan digunakan untuk menghitung nilai bilangan Reynolds dari blade, dapat ditulis dalam persamaan 6 .

$$
R_{e_{b}}=\frac{w_{u} \text { e }}{E_{v}}
$$

Dimana ${ } B_{\tilde{*}_{b}}$ adalah bilangan Reynold, ${ }^{c}$ adalah panjang chord blade dan ${ }{ }_{v}$ adalah viskositas kinematik.

Sudut serang blade dapat dihitung dengan menggunakan persamaan 7.

$$
\alpha=\arcsin \left(\frac{\cos \theta \cos \alpha_{0}-(T \sin -\sin \theta) \sin \alpha_{0}}{\sqrt{(T \sin -\sin \theta)^{2}+\left(\cos \theta^{2} \theta\right)}}\right)
$$

Dimana ${ }^{\alpha}$ adalah sudut serang blade yang merupakan sudut yang dibentuk antara chord blade dengan arah kecepatan angin resultan. ${ }^{\alpha_{0}}$ adalah sudut serang awal.

Untuk menghitung besar torsi dari blade, gaya lift dan drag dinyatakan dalam komponen arah tangensial dan komponen arah normal (radial). Koefisien gaya arah tangensial dan normal ditulis dalam persamaan 8a-b.

$$
\begin{aligned}
& C_{\mathrm{m}}=C_{l} \cos \alpha+C_{d} \sin \alpha \\
& C_{\mathrm{t}}=C_{l} \sin \alpha+C_{\mathrm{d}} \cos \alpha
\end{aligned}
$$

Dimana $C_{n}$ dan $C_{t}$ adalah koefisien gaya normal dan tangensial, dan $C_{l}$ dan $C_{d}$ adalah koefisien gaya lift dan drag.

Faktor gangguan pada daerah upstream dapat dihitung dengan persamaan 9. 


$$
a_{\mathrm{w}}=\frac{\pi}{f_{\mathrm{up}+\pi}}
$$

Dimana $f_{\text {up }}$ adalah fungsi yang menyatakan karakter aliran pada daerah upstream yang dinyatakan dalam persamaan 10 .

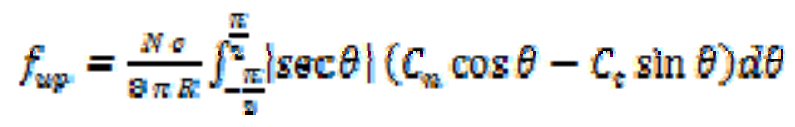

$\operatorname{Dimana}^{N}$ adalah jumlah blade.

Gaya tangensial dan gaya normal merupakan fungsi dari ${ }^{\theta}$, dapat dihitung dalam persamaan 11a-b.

$$
\begin{aligned}
& F_{n}(\theta)=\frac{1}{2} \rho c L W^{2} C_{n} \\
& F_{t}(\theta)=\frac{1}{2} \rho c L W^{2} C_{t}
\end{aligned}
$$

Dimana $F_{n}$ dan $F_{z}$ adalah gaya normal dan tangensial, ${ }^{\rho}$ adalah kerapatan udara, ${ }^{c}$ adalah blade chord, ${ }^{L}$ adalah panjang blade dan ${ }^{W}$ adalah kecepatan angin relatif.

Torsi yang dihasilkan oleh blade dapat dihitung dengan menggunakan persamaan 12 .

$$
Q(b)=\frac{1}{2} \rho \in R E C_{i} W^{2}
$$

Torsi rata-rata yang dihasilkan pada daerah upstream dapat dihitung dengan persamaan 13.

$$
Q_{Q v}=\frac{N}{2 \pi} \int_{-\frac{\pi}{2}}^{\frac{\pi}{2}} Q(\theta) d \theta
$$

Koefisien torsi rata-rata pada daerah upstream dapat dihitung dengan persamaan 14.

$$
C_{G_{\alpha V}}=\frac{Q_{\omega V}}{\frac{\pi}{2} \rho V_{Q}^{2} S R}
$$

Dengan diketahui nilai $C_{q_{a v}}$ maka koefisien power untuk daerah upstream dapat dihitung dalam persamaan 15 .

$$
C_{p_{u}}=C_{q_{\alpha v}} T S R
$$

Untuk torsi rata-rata dan koefisien power dari rotor pada daerah downstream dihitung dengan menggunakan cara yang sama (pers.2.17-2.19). Total koefisien power dari rotor dihitung dengan persamaan 16.

$$
c_{\gamma_{t}}=c_{\gamma_{u}}+c_{\gamma_{d}}
$$

Dimana $C_{\mathbb{F}_{\mathbb{d}}}$ adalah koefisien power dari rotor pada daerah downstream.

\section{Hasil dan Pembahasan}

Proses modifikasi bentuk bilah rotor VAWT dimulai dengan penentuan sudut puntir dan perhitungan sudut untuk setiap bagian dari masing-masing bilah sehingga didapatkan bentuk bilah yang memuntir sesuai yang diinginkan. Sudut puntir yang akan digunakan adalah $45^{\circ}, 60^{\circ}, 75^{\circ}, 90^{\circ}, 105^{\circ}, 120^{\circ}$. Sudut puntir dipilih mengacu penelitian sebelumnya [3] dan ditambahkan sudut lainnya sampai $120^{\circ}$ yang merupakan besar sudut antara bilah VAWT 
dengan interval $15^{\circ}$. Setelah sudut puntir ditentukan, maka dilakukan pembagian dari tiap bilah untuk mempermudah dalam proses pemodelan dan pembuatan purwarupa VAWT. Bilah VAWT dibagi menjadi 20 bagian untuk mendapatkan hasil puntiran yang halus, tiap tiap bagian memiliki sudut relatif terhadap posisi awal bilah. Spesifikasi geometri hasil modifikasi bentuk bilah ditunjukkan pada Tabel 1.

Tabel 1. Geometri Bilah Rotor VAWT Modifikasi

\begin{tabular}{|c|c|c|c|c|c|c|c|}
\hline \multirow{2}{*}{ Bagian } & \multirow{2}{*}{ Tinggi (m) } & \multicolumn{6}{|c|}{ Sudut Puntir $\left({ }^{0}\right)$} \\
\hline & & 45 & 60 & 75 & 90 & 105 & 120 \\
\hline 1 & 0 & 0 & 0 & 0 & 0 & 0 & 0 \\
\hline 2 & 0,036 & 2,25 & 3 & 3,75 & 4,5 & 5,25 & 6 \\
\hline 3 & 0,072 & 4,5 & 6 & 7,5 & 9 & 10,5 & 12 \\
\hline 4 & 0,108 & 6,75 & 9 & 11,25 & 13,5 & 15,75 & 18 \\
\hline 5 & 0,144 & 9 & 12 & 15 & 18 & 21 & 24 \\
\hline 6 & 0,18 & 11,25 & 15 & 18,75 & 22,5 & 26,25 & 30 \\
\hline 7 & 0,216 & 13,5 & 18 & 22,5 & 27 & 31,5 & 36 \\
\hline 8 & 0,252 & 15,75 & 21 & 26,25 & 31,5 & 36,75 & 42 \\
\hline 9 & 0,288 & 18 & 24 & 30 & 36 & 42 & 48 \\
\hline 10 & 0,324 & 20,25 & 27 & 33,75 & 40,5 & 47,25 & 54 \\
\hline 11 & 0,36 & 22,5 & 30 & 37,5 & 45 & 52,5 & 60 \\
\hline 12 & 0,396 & 24,75 & 33 & 41,25 & 49,5 & 57,75 & 66 \\
\hline 13 & 0,432 & 27 & 36 & 45 & 54 & 63 & 72 \\
\hline 14 & 0,468 & 29,25 & 39 & 48,75 & 58,5 & 68,25 & 78 \\
\hline 15 & 0,504 & 31,5 & 42 & 52,5 & 63 & 73,5 & 84 \\
\hline 16 & 0,54 & 33,75 & 45 & 56,25 & 67,5 & 78,75 & 90 \\
\hline 17 & 0,576 & 36 & 48 & 60 & 72 & 84 & 96 \\
\hline 18 & 0,612 & 38,25 & 51 & 63,75 & 76,5 & 89,25 & 102 \\
\hline 19 & 0,648 & 40,5 & 54 & 67,5 & 81 & 94,5 & 108 \\
\hline 20 & 0,684 & 42,75 & 57 & 71,25 & 85,5 & 99,75 & 114 \\
\hline
\end{tabular}




\begin{tabular}{|l|l|l|l|l|l|l|l|}
\hline 21 & 0,72 & 45 & 60 & 75 & 90 & 105 & 120 \\
\hline
\end{tabular}

Selanjutnya, dilakukan analisis aerodinamika rotor turbin angin dengan menggunakan bantuan software QBlade yang berbasis metode Double-Multiple Stream-tube (DMS). Dalam proses analisis, langkah pertama yang dilakukan adalah memodelkan rotor turbin angin untuk masing-masing sudut puntir menggunakan software QBlade seperti pada Gambar 4.



Gambar 4. Model Rotor Turbin Angin Bilah Puntir $\left(45^{\circ}, 60^{\circ}, 75^{\circ}, 90^{\circ}, 105^{\circ}, 120^{\circ}\right)$

Dari model yang telah dibuat pada Gambar 4 dilakukan analisis rotor dengan kecepatan angin $2,5 \mathrm{~m} / \mathrm{s}$ sesuai desain awal [5] dan variasi parameter nilai TSR untuk mendapatkan perbandingan nilai koefisien power (Cp). Hasil analisis dapat dilihat pada Gambar 5.

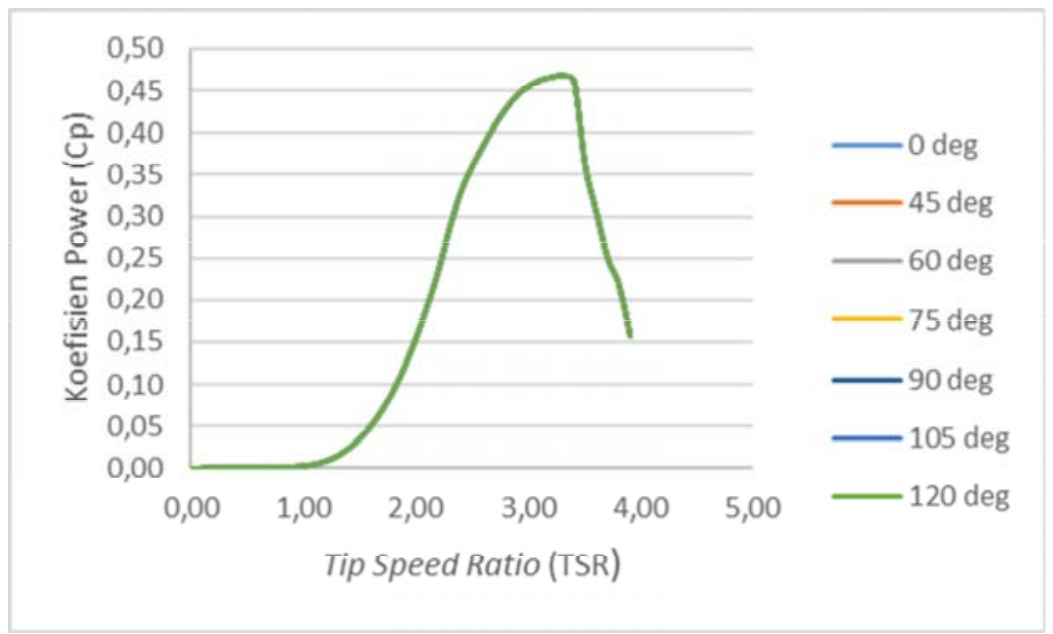

Gambar 5. Grafik Hubungan Koefisien Power dengan TSR

Dari Gambar 5 terlihat bahwa bentuk puntir tidak mempengaruhi nilai koefisien power turbin angin yang dihasilkan rotor sehingga dapat disimpulkan dari hasil analisis bahwa power yang dihasilkan rotor turbin angin tidak berubah dengan modifikasi bentuk bilah rotor dari lurus menjadi bentuk puntir. Selanjutnya, turbin angin dianalisis untuk melihat pengaruh perubahan bentuk bilah terhadap parameter torsi rotor. Hasil analisis dapat dilihat pada Gambar 6. 


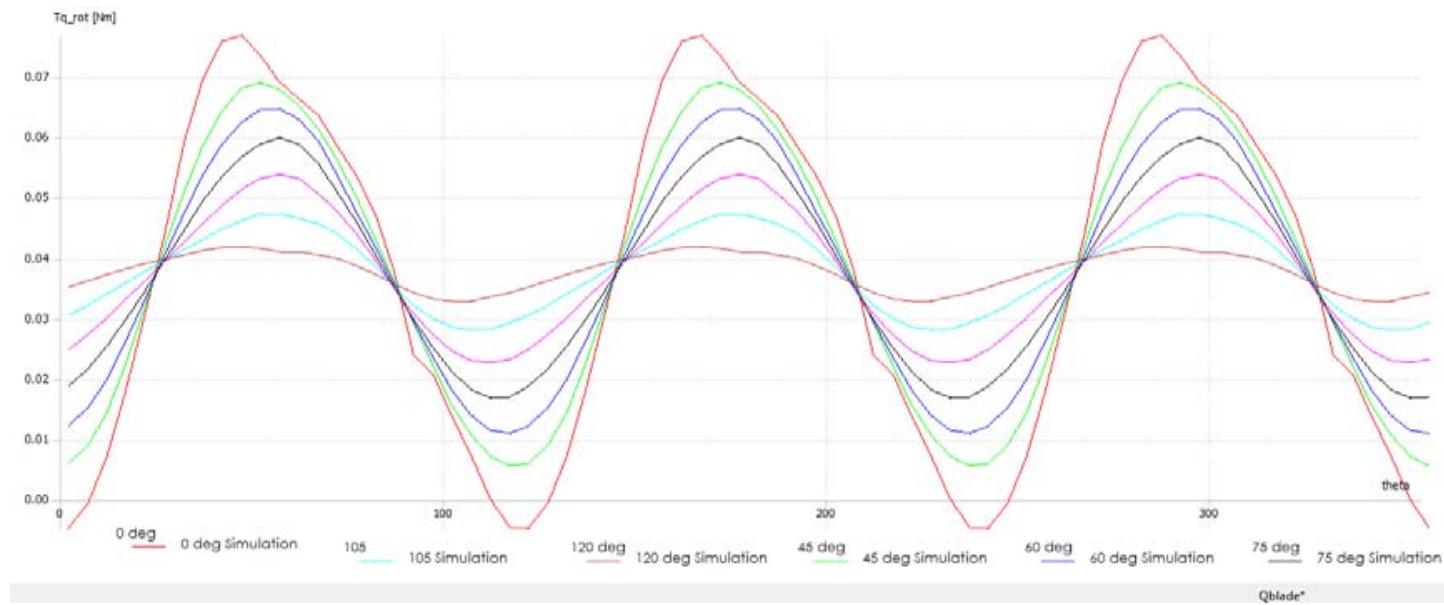

Gambar 6. Grafik Hubungan Torsi Rotor dengan Sudut putar

Dari Gambar 6 terlihat bahwa torsi yang dihasilkan oleh bilah lurus memiliki nilai maksimal dibandingkan dengan bilah puntir untuk semua sudut puntir, akan tetapi pada sudut putar tertentu $\left(0^{\circ}, 120^{\circ}, 240^{\circ}, 360^{\circ}\right)$ nilai torsi yang dihasilkan negatif (berlawan), sehingga akan menyebabkan penurunan performa turbin itu sendiri, hal ini tidak terjadi pada bilah puntir dimana torsi yang dihasilkan semuanya positif (searah), sehingga dapat mempertahankan putaran turbin yang dapat menghasilkan power yang konstan. Dari semua sudut puntir yang dianalisis, dapat disimpulkan berdasarkan hasil analisis pada gambar 6 bahwa sudut puntir yang menghasilkan nilai torsi besar dan positif untuk semua sudut putar adalah sudut puntir $45^{\circ}$, sehingga hasil modifikasi bilah rotor VAWT dari bentuk lurus menjadi bentuk puntir adalah bilah rotor dengan sudut puntir $45^{\circ}$.

\section{Kesimpulan}

Hasil analisis performa rotor menunjukkan bahwa bentuk puntir bilah tidak mempengaruhi besar nilai koefisien power turbin angin yang dihasilkan rotor, akan tetapi torsi yang dihasilkan oleh bilah puntir untuk semua sudut putar memiliki arah yang sama yang dapat mempertahankan putaran turbin yang menghasilkan power yang konstan, sebaliknya untuk bilah bentuk lurus tidak menghasilkan power yang konstan. Dari semua sudut puntir yang dianalisis, dapat disimpulkan bahwa sudut puntir yang menghasilkan nilai torsi besar dan positif untuk semua sudut putar adalah sudut puntir $45^{\circ}$, sehingga hasil modifikasi bilah rotor VAWT dari bentuk lurus menjadi bentuk puntir adalah bilah rotor dengan sudut puntir $45^{\circ}$.

\section{Daftar Pustaka}

[1] Cooper, P. 2010. Development and analysis of vertical-axis wind turbines. WIT Transactions on State of the Art in Science and Engineering, Vol 44. WIT Press. Inggris.

[2] Paraschivoiu, I. 2002. Wind Turbine Design With Emphasis on Darrieus Concept. Presses internationales Polytechnique. Perancis.

[3] MD.Saddam Hussen, Dr. K. Rambabu, M. Ramji, E. Srinivas. 2015. Design and Analysis of Vertical Axis Wind Turbine Rotors. International Journal on Recent Technologies in Mechanical and Electrical Engineering (IJRMEE), Volume 2, Issue 9, Hal.054-062. India

[4] Buyung Junaidin. 2017. Perancangan Vertical Axis Wind Turbine (VAWT) Skala Kecil. Jurnal Ilmiah ANGKASA, Volume IX, no.2, hal.29-38. STTA. Yogyakarta. 